Western University Scholarship@Western

Department of Economics Research Reports

Economics Working Papers Archive

1978

\title{
Difficulties with European Monetary Union
}

David Laidler

Follow this and additional works at: https://ir.lib.uwo.ca/economicsresrpt

Part of the Economics Commons

Citation of this paper:

Laidler, David. "Difficulties with European Monetary Union." Department of Economics Research Reports, 7803. London, ON: Department of Economics, University of Western Ontario (1978). 
RESEARCH REPORT 7803

DIFFICULTIES WITH EUROPEAN

MONETARY UNION

by

David Laidler

February 1978 
DIFFICULTIES WITH EUROPEAN MONETARY UNION

by

David Laidlex

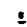

Revised version of a paper presented at the Leuven Conference on European Monetary Union, November 24-26, 1977. I am grateful to Michele Fratianni, Peter Howitt, Pieter Korteweg, Michael Parkin and George zis for comments on an earlier draft. 


\section{INTRODUCTION}

It is now two years since the authors of the All Saints' Day Manifesto (Basevi et al. (1975)) advanced their proposals for European Monetary Union. The Manifesto itself, and subsequent writings by at least one of its authors (Parkin (1976)) make it clear that they envisage themselves as planning, not for some distant time in the future, but for the present. Their scheme is one that they would have implemented immediately in 1975, and presumably one that they would implement now had they the power to do so. ${ }^{1}$ Given the renewal of interest within the EEC Commission in the goal of monetary union, it is of particular importance that the goal itself, and the methods that have been proposed to achieve it, be subject to critical scrutiny and debate. This paper seeks to contribute to such a debate. The Manifesto's authors have claimed that there is no case to be made against immediately moving towards European Monetary Union (EMU). It is my contention that there are serious problems involved in such a move, particularly an immediate one. To proceed towards EMU without a thorough analysis of these problems is to risk its failure. Whether one opposes or supports EMU, one can agree that a botched attempt at achieving it is something to be avoided. The arguments that follow stop far short of being a blanket condemnation of all aspects of the case put by the proponents of EMU. Rather they are advanced in the hope of tempering political enthusiasm for EMU by a little economic realism.

\section{COMMON GROUND}

To begin with, there is no dispute that, ceteris paribus, it would be more efficient for the trading system of the EEC (or of the whole world, for that matter), to use a common currency rather than a collection of national currencies. The existence of a multiplicity of currencies between which exchange rates are not rigidly fixed does introduce an extra element of risk into 
foreign trade; that risk can be mitigated by the activities of speculators in specialized foreign exchange markets, but such markets do consume real resources; even if exchange rates are rigidly fixed, there are extra transactions costs involved in moving between currencies; and so forth. I agree with all this. I would also immediately concede that there is no case to be made for maintaining a system of national currencies whose exchange rates one for another are rigidly fixed for all time. A group of nations which had moved to such a system could only gain by moving to a single currency. The case against a single currency is thus the case for maintaining some degree of exchange rate flexibility. ${ }^{2}$

Given the undoubted gains from having a single currency, any case against it must rest on the proposition that the move from a degree of exchange rate flexibility to a common currency does not leave the other things equal, but rather generates more than offsetting losses elsewhere. Let it be noted then that I agree with the proponents of EMU on one important issue concerning the losses to be expected from it, an issue that involves two propositions, one true, and one which I regard as false. The true proposition is that exchange rate flexibility permits different countries to sustain different inflation rates, and the one which I believe to be false is that this in turn will permit them to sustain different unemployment rates. From these two premises it is frequently argued that, given that different nations have different "tastes" vis-à-vis inflation and unemployment, or a different capacity to combine them, EMU would force sub-optimal inflation-unemployment combinations on the nations participating in it.

Parkin (1976) has argued convincingly that whether or not one accepts the second premise of this chain of reasoning depends upon one's view of the causes of inflation. The premise is consistent with an institutional approach 
to explaining the causes of inflation, or with one based upon the PhillipsLipsey theory of the relationships between excess demand, unemployment, and inflation. It is inconsistent with a belief in a "natural unemployment rate" whose value is independent of (or positively related to) the anticipated inflation rate, and with a belief in the proposition that in the long run the actual and anticipated inflation rates are equal to each other. Since I agree with Parkin that these two propositions do seem to be consistent with a considerable amount of empirical evidence, I also agree with him that the foregoing commonly advanced argument against EMU is invalid. ${ }^{3}$

The final opinion that I share with the proponents of EMU may be put as follows. Monetary union is seen by many people on both sides of the debate as one part of a much more fundamental economic and political union that might be achieved within the EEC. The arguments for and against such a union range far beyond economics, and in my view, issues concerning EMU are trivial when viewed in such a context. If the aim is to turn the EEC into a federal state, then there is an extremely strong case for regarding a common currency as an important institution for that state to create. This paper is not the place to go into the pros and cons of forming a United States of Europe. Suffice it to say that in what follows I will in no way quarrel with those who argue that EMU should be one of the ultimate goals of those seeking to create such an entity, nor will I have anything to say in support of those who oppose EMU because they are opposed to a broader union. I will quarrel with the view that, given that EMU is a desirable ultimate goal, now is a good time to begin to move towards it, and that the means proposed in the All Saints' Day Manifesto promise an easy path towards its realization.

III. THE CASE AGAINST THE ALL SAINTS' DAY MANIFESTO My basis for arguing that it is undesirable to move towards EMU now 
1) would be the observation that rates of inflation within the EEC are currently (Autumn 1977) extremely disparate, ranging from a low of 48 in Germany to a high of 198 in Italy. The authors of the All Saints' Day Manifesto recognize, indeed take as a starting point for their own proposals, that this fact precludes any rapid approach to monetary union through an orthodox sequence of events beginning with the harmonization of inflation rates, proceeding to the fixing of exchange rates between national currencies, with these in turn ultimately being replaced by a common currency. They recognize that it is politically impossible, not to mention economically undesirable, to get the low inflation countries to drive their inflation rates up to the levels prevailing in Britain and Italy, and equally impossible and undesirable for those high inflation countries to endure the transitional unemployment that would have to accompany a rapid diminution of their own inflation rates. However those authors do claim that their proposals, which involve the issue of a parallel European currency, enable such problems to be bypassed.

As Parkin (1976) has noted, our knowledge of the economics of parallel currencies, particularly detailed empirical knowledge, is rather meagre, although Vaubel's work (1978) promises to make an important contribution here; any arguments about this matter must be tentative. Nevertheless, let me assert immediately that I am not convinced of the economic viability of the proposals advanced in the All Saints' Day Manifesto.

The proposals are simple enough. A European Central Bank is to be set up to issue a new currency called the Europa. Each member government of the EEC is to permit its nationals freely to use the Europa as a means of exchange, store of value and unit of account, in short as money, as and if they see fit. Initially the Europa is to be put into circulation only by means of the new European Bank offering to exchange it in unlimited quantities for a basket of the national currencies of EEC members. ${ }^{4}$ In order to ensure that the purchasing 
power of the Europa remains constant, the price at which it is exchanged against this basket will be adjusted at regular intervals in proportion to the change in the purchasing power over goods and services of the various currencies that make it up over the interval in question. It is claimed that to introduce a new currency in this way will ultimately drive inflating national currencies out of circulation. The Europa will thus naturally evolve as the only European currency. At that stage, the authors of the Manifesto recognize that Europas will have to be issued in accordance with some rule about the behavior of their nominal quantity outstanding that will enable the constancy of their purchasing power to be maintained. In short, the scheme is claimed to combine the advantages of ensuring the achievement of a common European currency, with those of ridding European countries of inflation by way of what amounts to a currency reform; and all of this is to happen as a result of voluntary choices made by private agents, rather than being imposed by any governmental authority. As the Manifesto puts it, "The adoption of the Europa requires one major political decision on the part of each National Government: to permit their residents to use and to hold Europas in competition with national money. The fate of the Europa, however, will be determined in the marketplace by the [sic] economic operators."

In fact, much more is required of national governments if the scheme is to be viable and successful. First, and fundamentally, if national currencies are to be driven from circulation, then national governments must cease issuing them. If the Manifesto's scheme cannot guarantee that, it cannot guarantee to achieve either of its ultimate goals. The basic difficulty here may be put as follows. There is no better incentive to make a national authority cease to issue its own currency than that there ceases to exist a group of willing holders of such a currency. One cannot generate revenue from issuing money which has no 
willing holders. Now it is true that the introduction of a purchasing power -guaranteed substitute currency would make the private sector of any economy less willing to hold an inflating national currency; the authors of the Manifesto seem--I say seem because they are not completely explicit on this matter--to believe that this very fact will force the national authorities to cease [issuing it. 5 However, their proposal makes the new European Bank a willing holder of the inflating national currency that will replace the private sector. From the point of view of any national monetary authority, it does not matter who holds its currency. It can extract revenue from anyone who does. (Although the revenue that can be extracted from the European Bank will come in the form of falling real indebtedness, rather than as a current flow of goods and ser$\mid$ vices.) Thus, the scheme proposed in the text of the Manifesto does not encourage $_{\text {national authorities to give up issuing their own currencies. }}$

We may pursue this matter from another angle. The European Central Bank is expected to issue a purchasing power guaranteed liability, and take in exchange for it the depreciating liabilities of national central banks. That of course is a recipe for making a continuous loss on its operations, that loss being equal to the inflation tax levied by national governments on the European Bank's holdings of their liabilities. The question arises as to how that loss is to be made good. Two possible schemes come to mind. First it could be made good by national governments in proportion to the Bank's losses from holding particular national currencies. Second, it could be shared among the EEC countries according to some other formula. The first situation would of course require a conscious decision on the part of all national monetary authorities to give up a part of the revenue that they earn from issuing money and the second would require a conscious decision on the part of some national monetary authorities to permit themselves to be taxed by others. In either instance, the 
decision in question would have to be taken as part and parcel of the agreement to participate in the setting up of the European Bank that would issue the Europa. To ask that national governments make st:ch a decision is to ask them to go far beyond simply permitting their own nationals to hold and trade in Europas, which the text of the Manifesto claims is the only step required of them to make the scheme viable. In fact, a footnote to Table 2 of the Manifesto shows that its authors have considered this problem, and have opted to have each national bank compensate the European Bank in proportion to the latter's holding of each national currency. The absence of any discussion of this issue from the text leaves the unwary reader ignorant of the extra, and serious, commitment that must be made by national authorities to surrender part of their revenue from money creation even before the scheme can be implemented.

The device for putting Europas into circulation by standing ready to trade them against national currencies at a price set by the Bank (though varying over time) lies at the root of the above difficulties. It also causes another problem. Suppose that some agreement is reached about who is to pay the tax levied by national central banks upon the European Bank, and suppose that the Europa does begin to circulate widely. Its price in terms of national currencies is supposed to be fixed with reference to the behavior of some general price level measured in terms of those currencies. Once the Europa is circulating widely, what exactly will be the meaning of a price level measured in terms of a national currency? If the market were left free to determine cross rates between the Europa and other currencies this would not be a problem, of course, but it is of the essence of the scheme proposed in the Manifesto that such rates are to be set by the European Bank. There is a discomforting aura of indeterminacy about the way in which the scheme will work at this point. At some stage, and long before other currencies are driven out of 
circulation, some other means must be found for controlling the issue of Europas, but the Manifesto does not tell us what it will be.

The problems discussed so far, namely the requirement that National Monetary Authorities make a prior commitment to surrender some revenue from money creation, and the indeterminacy of the transition from national currencies to a common one, both arise from the institutional arrangement whereby unlimited quantities of Europas are to be traded at a stated price against national currencies. If the Europa is to be purchasing power guaranteed, an alternative mode for its issue would be at a fixed price against warehouse receipts for a selected commodity, or bundle of commodities. Such a mode of issue would tie down the price level of the chosen commodity bundle in terms of the Europa, regardless of the quantity issued. As to its price in terms of other currencies, that could either be left to respond to market forces, or it could be fixed in some other way. In either event that would be a decision to be left to the discretion of national central banks. Given that the price of goods in terms of the Europa was fixed, they would be able to decide whether or not to intervene in the market for Europas with their own currencies and they would have no obligation to make good losses made by the European Bank on any holding of their liabilities.

In current circumstances we can immediately rule out the feasibility of national central banks each adopting a fixed exchange rate against a constant purchasing power Europa. If they were able and willing to do that, they would be able and willing to do it vis-à-vis each other's national currencies. The first step in what might be termed the conventional path towards EMU could then be taken immediately, and without resort to any such device as the Europa. Only a scheme in which market forces predominate in determining the Europa's price in terms of national currencies is viable if the aim is to get it into circulation now. However, when markets are permitted to determine the relative prices of 
different currencies, Gresham's Law ceases to operate. Bad and good monies can continue to circulate together indefinitely when their relative prices are free to vary. Thus, to issue the Europa in the way I have just envisaged would add one more to the number of EEC currencies, albeit a constant purchasing power one, but it would not necessarily advance the establishment of a single European currency.

However, I would go further than that, and argue that more harm than good would be done in present circumstances by issuing the Europa in this way. I readily concede that Parkin's arguments, about how a lower rate of inflation could be achieved without any transition costs if agents moved to striking bargains in terms of a constant purchasing power currency, are formally correct. ${ }^{6}$ Indeed they are ingenious. However they completely ignore an institutional factor of great importance, namely that economic agents pay taxes to national governments. The laws and accounting conventions whereby tax liabilities are computed are currently set out in terms of national currencies. As the debate about inflation accounting attests, the difficulties involved in devising a new set of conventions are enormous, and provide what I would conjecture to be more than adequate incentives to ensure that, with current inflation rates, national currencies would remain the dominant unit of account even in the presence of the Europa. That in itself would help preserve them as means of exchange and stores of value; and why should governments who have an interest in maintaining their abilities to raise revenue from money creation alter the legal framework that helps maintain that ability? In short, I find it difficult to believe that a constant purchasing power Europa would become a widely used unit of account (or means of exchange at least in intra-national transactions) and hence cannot give much practical weight to Parkin's arguments about the advantages that would accrue if it was so used. 
However, I have no difficulty in believing that the Europa could become a much sought after store of value. There is no need to dwell on the attractions of a riskless zero real rate of return security for residents of such countries as Britain and Italy. This would lead to two interrelated problems. First, to the extent that the introduction of Europas reduced the demand for national currencies, it would reduce the revenue accruing to the monetary authority at any rate of inflation. For a given public sector cash requirement, taxes and other borrowing would have to increase. Second, because the Europa would offer a far higher real return than otherwise comparable securities, its presence would put upward pressure on the interest rates, both real and nominal, at which the private sector could borrow. Neither of these effects is desirable given the current acutely depressed state of real economic activity; nor does it seem to me to be helpful to argue, as does Parkin, that they could be offset by expansionary fiscal policy, with the increases in already inflated public sector borrowing requirements and depressing effects on an already depressed private sector that that would entail. 7

In short, I am not convinced that there is any means, in the current circumstances, whereby the approach to European Monetary Union can be eased by the issue of a European currency to circulate alongside national currencies. The scheme proposed in the All Saints' Day Manifesto glosses over the extent of the prior agreement required to implement it and is not fully worked out; alternatives either are not viable, or will fail to lead to the voluntary disappearance of national currencies, while themselves having unfortunate side effects. In the next section of this paper I shall deal with the case against a rapid approach to EMU by other, more orthodox, means.

IV. THE QUESTION OF AN EARLY CURRENCY REFORM

It has already been argued that it is not viable to approach EMU by 
way of first establishing fixed exchange rates amongst national currencies and then phasing these currencies out, if a rapid establishment of a common currency is what is required. There is one alternative that does, however, appear to be viable at first sight. The authors of the All Saints' Day Manifesto recognize, correctly, that the transitional unemployment costs associated with rapidly reducing the rates of price increase in high inflation countries can be avoided by a currency reform. Indeed, their scheme for a parallel currency was supposed to provide the same advantages as such a reform. We have seen that there are other problems associated with that scheme, but the basic insight remains valid: why not then establish EMU by a once and for all currency reform? Instead of issuing the Europa as a parallel currency, why not establish it as a substitute currency? ${ }^{8}$

Now of course such a step would require a great deal of national governments. Each one would have to agree to give up the right to issue its own national money--except perhaps on the Scottish model of a one hundred percent reserve requirement with convertibility on demand; each one would have to agree to declare the Europa legal tender domestically; each one would have to subscribe to whatever arrangements were made to ensure that the nominal rate of expansion of the new currency was compatible with long-term stability in its purchasing power; and so on. All this would be extraordinarily difficult to arrange. Indeed many would argue that it would be politically impossible to do so in the present climate. However, Parkin has warned us against confusing arguments to the effect that certain things will not happen with arguments to the effect that they ought not to happen. ${ }^{9}$ For an economist to fail to recommend an economically viable policy on the grounds that it is not politically acceptable at a particular time is to help ensure that the policy never will become politically acceptable. Let us therefore discuss this option on its economic merits. 
There is much to recommend a quick approach to EMU by way of a currency reform. The inflation expectations whose inertia underlies the real stagnation that accompanies any significant reduction in an inflation rate must, by their very nature, be specific to a particular currency. If that currency ceases to exist and is replaced by a new one, then the formation of expectations must also start afresh. That is the essence of the case for tackling inflation by way of a currency reform. Although the case is broadly correct, it fails to get to grips with certain transitional problems that would arise from introducing a new currency in the contemporary European context. Inflation, though it has been severe, has been far from catastrophic over the last few years. In hyperinflations long-term contracts, whether in labor markets or capital markets, seem to vanish. Though in the last few years the period for which wage bargains have been struck has shortened, and although the long end of the capital market has seen its activities curtailed, there would nevertheless be a major problem as to what to do about the terms of contracts that had been struck in terms of a depreciating unit of account, with due allowance having been made for expectations about its depreciation, if that unit of account was suddenly replaced by a new one of constant purchasing power. If a three-year consumer loan, denominated in sterling, bears a nominal interest rate of $20 \%$, what would be the appropriate rate in Europas? And what about the terms of a 25-year fixed interest mortgage? I am not suggesting that problems such as these are insuperable, of course, but I am suggesting that the costs of dealing with them, or those imposed by failing to deal with them, must be offset against the benefits of tackling moderate inflation by way of a currency reform. They would not, after all, arise if EMU was achieved by a sequence of events that involved, as a first step, the gradual harmonization of national inflation rates at a desirable level. However, it is not the costs that a currency reform imposes upon the 
private sector that raise the most serious questions about the desirability of achieving EMU by such a means. Rather it is the constraint that it imposes upon the public sector. An excessively rapid pace of monetary expansion does not occur fortuitously in a modern economy. It arises because the government, having difficulty in meeting its budget constraint by other means, resorts to generating revenue by money creation. A currency reform that is not accompanied by measures to make it possible for the public sector's budget constraint to be met by other means is going to fail, and having failed reduces the chances of any future reform being successful. If EMU is to be achieved by such a route, then, it had better be achieved at the first attempt.

To the extent that inflation itself is a major contributor to the government's fiscal problems, a currency reform itself will make a major contribution to the government's ability to meet its budget constraint without resorting to further inflation. Such was the case with the Weimar hyperinflation where lags in tax payments interacted with rising prices to produce enormous falls in the real value of government revenue, which in their turn forced the government into further money creation. To the extent that a currency reform coincides with other changes that affect government finance, there is also reason to suppose that it will be successful. Such was the case with China in 1948 where the accession of a new government resulted from the end of the Civil war, the financing of which itself had been the major cause of the previous regime's resorting to the printing press. ${ }^{10}$ However, in contemporary Europe, neither of the above conditions seems to hold. Money creation is funding deficits, but a currency reform will not do anything to reverse those deficits, nor does a move to EMU promise to do anything in and of itself to reduce them.

If a currency reform is to be an effective means of rapidly approaching EMU in current circumstances, and if the danger of the Europa itself becoming 
an inflating currency is to be avoided, the governments of individual EEC countries must either find an alternative source of revenue to money creation, or cut down on their expenditures. We have already noted above the depressed state of the real economies of EEC members, and have commented on the undesirability of any rapid contraction of fiscal policy in current circumstances-however desirable it might be in the long run to shrink the share of government in the economy. These considerations are relevant here, because unless it is argued that currency reform and EMU will, because of their effects on the "animal spirits" of the private sector, generate a boom there, the fiscal restraint that would have to go along with such measures could only serve to depress further what are already excessively depressed economies. Thus, though EMU through currency reform is a viable alternative to gradualism in monetary policy under a given currency, and cannot be opposed on narrow monetary grounds, its adoption in current circumstances might require the abandonment of gradualism in fiscal policy, and that is much harder to defend.

Even if the foregoing objections to EMU were irrelevant, if national finances were already in order and national inflation rates harmonized at low levels, it would be wrong to pretend that all objections to a rapid movement to EMU would have disappeared. It could, and should, still be argued that monetary union would better be achieved after, or simultaneously with, fiscal union rather than prior to it. I have discussed the issues involved here elsewhere (Laidler (1976)) and there is no need to go into the arguments in elaborate detail here. It will suffice to describe them briefly. The first argument is somewhat esoteric; it rests on the simple proposition that money creation, being a source of revenue to its issuer, is, from the point of view of the promotion of economic welfare, best analyzed and regulated as part of the overall system of taxation of an economic entity. Such a viewpoint leads at once to the conclusion that 
monetary union should go along with fiscal and political union rather than being regarded as a separate and prior goal.

The other arguments are of more practical importance, but lead to the same conclusion. These arguments rest on the belief that economies are subjected to what are usually termed "real shocks" as well as to nominal shocks, and on the belief that, in the short run, variations in the quantity of money influence real as well as nominal variables. Though it is readily admitted that there is nothing that can be done with monetary policy to offset the effects of real shocks in the long run, it nevertheless follows from the foregoing assertions that the nature of the transition from one real equilibrium to another can be influenced by the behavior of the quantity of money, and would differ depending upon whether a particular country enjoyed domestic monetary autonomy combined with exchange rate flexibility, or was a member of a currency union.

To see why this might be so, consider the response of an economy to a shock which requires a change in the level of real wages relative to those ruling elsewhere in the currency union to which it belongs. If the economy is a member of a currency union, its price level is given, so it is money wages that must adjust to accommodate such a shock. Under domestic monetary autonomy an alternative means of adjustment would involve exchange rate and price level variations. If we apply to shese alternatives Hicks" (1974) distinction between "fix" and "flex" price markets, and if it is agreed that the labor market has far more "fix" price characteristics than does the foreign exchange market, then it can be argued that the adjustment involving exchange rate and price level changes is likely to be smoother, and less characterized by variations in real income and employment, than that which requires the burden of adjustment to fall upon money wages. 
Now this amounts to saying that even if the process of transition to a common currency is costless, there are certain disadvantages to be offset against the admitted advantages that a country gains from belonging to a currency union. These arguments are not however a blanket objection to a particular country ever joining a currency union under any circumstances. Moreover, whatever force they may have is weakened if there exists other means than monetary autonomy and exchange rate variability to cope with the real income and employment consequences of whatever real shocks might fall upon a particular economy. We do not often hear it argued that geographical regions of particular nations would be better off to abandon the national currency and adopt their own, even though real shocks do impinge differently upon different regions. The reason for this is surely that an individual nation is a fiscal union as well as having a common currency. Individual countries typically do make provision within their fiscal systems for interregional transfers of resources to take place, both on a long-term basis, and on a short-run basis in response to specific difficulties. And this is not to mention the fact that individual regions do have their representatives in the national legislature to help ensure that their particular problems are known about, and responded to.

With fiscal and political union then, there are created a set of institutions, which provide an alternative to those associated with monetary autonomy, for dealing with some of the economic problems that arise for particular regions within the union. Thus the case for maintaining separate currencies is severly weakened by the creation of such institutions--indeed positive arguments in favor of a currency union, that need no elaboration here, arise from the creation of such a union. It is, after all, easier to devise and implement a common fiscal policy when there is but one unit of account and means of exchange for the whole fiscal union. ${ }^{11}$ 


\section{v. CONCLUSIONS}

The conclusions that seem to follow from the arguments presented in this paper are easily summarized. First, it would be desirable to aim for EMU as and if fiscal and political union are also achieved, rather than to attempt to achieve this aspect of European unification earlier. I would argue for this position even if every member of the EEC had already achieved full employment and price stability. However, I would concede that in such circumstances there is considerable scope for argument about this conclusion. I would be much less willing to give up ground on the proposition that, given the current wide disparity of inflation rates between the countries of the EEC, and given the depressed state of the real economies of those same countries, the side effects of attempting to achieve an early monetary union in present circumstances make that course of action economically undesirable. 
FOOTNOTES

${ }^{1}$ See Parkin (1976), p. 4.

2 The arguments of the preceding paragraph have been made in greater detail in Laidler (1976).

${ }^{3}$ It should be noted that sumner (1976) contains the fullest account of the issues dealt with in the preceding paragraph.

4 On this see the final section of the Manifesto as printed in The Economist.

${ }^{5}$ See the penultimate section of the Manifesto as printed in The Economist.

${ }^{6}$ See Parkin (1976), pp. 13-15.

${ }^{7}$ See Parkin (1976), p. 15 .

${ }^{8}$ It is worth noting that the authors of the Manifesto considered this possibility and rejected it on the grounds that it would create a stabilization crisis in most countries. Perhaps they had in mind the arguments advanced below.

${ }^{9}$ See Parkin (1976), p. 4.

${ }^{10}$ The examples of Weimar and China are not chosen at random. They are the examples of successful currency reforms cited by Parkin (1976).

${ }^{11}$ One need only remind the reader of the difficulties of implementing the Common Agricultural Policy of the EEC under floating exchange rates in order to convey to him the weight of this argument. 
REFERENCES

Basevi, G., Fratianni, M., Giersch, H., Korteweg, P., O'Mahony, D., Parkin, M., Peeters, T., Salin, P., and Thygesen, N., "A Currency for Europe: The All Saints' Day Manifesto for European Monetary Union," The Economist, November 1, 1975.

Hicks, J. R., The Crisis in Keynesian Economics, Oxford: Blackwell, 1974 . Laidler, D., "Concerning Currency Unions," paper presented at the Fourth University of Paris-Dauphine Conference on International Monetary Economics, Fort-de-France, Martinique, November 1976, University of Western Ontario Research Report 7618 (mimeo).

Parkin, M., "Monetary Union and Stabilization Policy in the European Community," Banca Nazionale del Lavoro Quarterly Review, September 1976, pp. 3-2I.

Sumner, M. T., "European Monetary Union and the Control of Europe's Inflation Rate," in Parkin, J. M. and Zis, G. (eds.), Inflation in the World Economy, Manchester: Manchester University Press, 1976.

Vaubel, R., "Strategies for Currency Unification, the Case for a European Parallel Currency and the Economics of Currency Competition," mimeo, Kiel, Institut fur Weltwirtschaft, 1978. 